\title{
The Impact of a Metacognitive Intervention using I.M.P.R.O.V.E. Model on Grade 7 Students' Metacognitive Awareness in Mathematics
}

\author{
Napoleon A. Montero III ${ }^{\text {a }}$, Levi E. Elipane ${ }^{\mathrm{b}}$ \\ ${ }^{a}$ De La Salle University- Manila, Philippines \\ ${ }^{a}$ T.C. Roberson High School, North Carolina, United States \\ ${ }^{\mathrm{b}}$ Philippine Normal University-Manila, Philippines \\ a*napoleon_monteroiii@dlsu.edu.ph
}

Article History: Received: 10 November 2020; Revised 12 January 2021 Accepted: 27 January 2021; Published online: 5 April 2021

\begin{abstract}
This study sought to investigate the impact of a Metacognitive intervention on Grade 7 students' Metacognitive awareness in Mathematics. Using Concurrent Action Research as the research design of the study, one heterogeneous Grade 7 class from a public high school in Metro Manila underwent a six-week Metacognitive Intervention using a structured Metacognitive instructional model called, I.M.P.R.O.V.E. (Introducing the new concepts; Metacognitive questioning; Practicing; Reviewing and Reducing difficulties; Obtaining mastery; Verification; and Enrichment). The quantitative aspect of the research included the assessment of the Metacognitive Awareness before and after the intervention period using the Jr. Metacognitive Awareness Inventory (Jr. MAI). On the other hand, student interviews, Focus Group Discussions (FGD) with the observers, and learners' outputs were examined in the qualitative aspect of the research. Results revealed that there were large, and huge significant differences between the pre-test and post-test results of the Jr. MAI. Moreover, the intervention gained affirmative responses from the teacher observers and student participants as a good intervention tool to enhance students' Metacognitive Awareness in Mathematics. Emergent issues on the utilization of the intervention were discussed such as: Questions that direct student learning; Enrichment of students' Metacognitive experience; and Use of reflections in Mathematics. Recommendations on improving the model utilization were also discussed which included: selection of topics where the I.M.P.R.O.V.E. is appropriate to be used; and emphasis of objectives as "today's target" in classrooms

Keywords: Metacognition, Metacognitive Awareness, Mathematics Achievement, I.M.P.R.O.V.E. Model, Metacognitive Intervention
\end{abstract}

\section{Introduction}

Quality education is viewed as any country's pillar of success. The need to attain a good quality of education has always been a major concern of the Philippine government. In fact, for the past years, the government regards the Education sector of the country as a top priority given the highest allocation of budget among all agencies as required by the 1987 Philippine Constitution [1]. Moreover, there has always been a move to reconstruct the system, whether in the structure of the curriculum, improvement of classroom facilities and equipment, or professional development of teachers [2]. For example, in 2004, the Commission of Higher Education in the Philippines adopted and promulgated policies and standards for undergraduate teacher education that is deemed to be aligned to classroom practice and be reconciled to various social dimensions that subsist in educational environments[3].

However, the education sector in the country faces several issues that need to be addressed. One of these is the academic achievement of the students particularly in Mathematics which was considered to be struggling in general, as manifested in the results of the previous national and international examinations.

Despite all the significant efforts made to improve the performance of the students in Mathematics, the country still remains among the least successful countries in the said field. However, to address this area of concern in the field of Mathematics Education, researchers must continue to look for possible solutions that would enhance the learners' Mathematics achievement

One popular idea in Mathematics Education that is recognized to be one of the most relevant predictors of student achievement in Mathematics and is deemed to be a solution to the current problem is the so called, 'thinking about one's thinking', also known as Metacognition.

Metacognition is formally defined as the learners' abilities to reflect upon their actions and thought, to predict their performances on various tasks and to monitor their current levels of mastery and understanding [4]. Researchers believe that Metacognition plays an important role in being successful in Mathematics. In the studies 
conducted by Acoba [5], Desoete [6], and Ozsoy [7], Metacognition is found to be significantly correlated with the Mathematics achievement of learners. For this reason, many researchers have sought to engage students in metacognitive thinking to improve their learning. This can be done through an integration of metacognitive strategies into the formal classroom instruction, also known as 'Metacognitive intervention.'

One specific instructional approach that can be used as a metacognitive intervention tool in Mathematics is the I.M.P.R.O.V.E. model. I.M.P.R.O.V.E. is an acronym which corresponds to all the teaching steps that constitute the method: Introducing the new concepts; Metacognitive questioning; Practicing; Reviewing and Reducing difficulties; Obtaining mastery; Verification; and Enrichment. It was developed by Mevarech, Z. \& Kramarski B. in 1997 with the purpose of providing students an environment where they can construct mathematical meaning by involving themselves in metacognitive conversations and eventually enhance their mathematical reasoning.

Hence, with the viewpoint that engaging students to classroom activities that make them reflect about the way they think and using a specific standard approach to do it would lead them to academic success, the researchers were led to investigate on the Metacognitive Awareness of students, and the impact of a Metacognitive intervention using I.M.P.R.O.V.E. model on their Metacognition.

The Metacognitive intervention of this study was anchored on the design principles of conducting metacognitive intervention programs by Lin [8], such as: “(1) to provide frequent opportunities for students to self-assess what they know and do not know; (2) to help students articulate their own thinking; (3) to foster a shared understanding of the goals for metacognitive activities; (4) to develop knowledge of the self-as-learner with respect to one's role in a specific culture." (p.34)

To be able to conduct this study, the researchers used a specific metacognitive instructional model that encompasses the essential aspects of developing learner metacognition and mathematical skills. The model is called, I.M.P.R.O.V.E., an acronym which corresponds to all the teaching steps that constitute the method: Introducing the new concepts, Metacognitive questioning, Practicing, Reviewing and Reducing difficulties, Obtaining mastery, Verification, and Enrichment. The theoretical foundation of this model was based on the three interdependent components that enhance mathematical ability: (1) metacognitive questioning and strategy acquisition; (2) cooperative learning, and (3) systematic provision of feedback-corrective-enrichment opportunities [9].

\section{Methodology}

Concurrent Action Research was employed in this study since an attempt was done to improve the teaching practice for the enhancement of student learning. Action Research is defined as a process of systematic inquiry that enables people to find effective solutions to real problems encountered in daily life [10].

The study was conducted in an intact heterogeneous Grade 7 class from a public high school in Metro Manila, Philippines. The participants were composed of 40 Grade 7 Students (19 males and 21 females).

The Metacognitive awareness of the student participants were initially examined through pre-testing using the Jr. MAI instrument. They underwent metacognitive training and were taught lessons in Grade 7 Mathematics using a Metacognitive instructional method called I.M.P.R.O.V.E. The instruction, metacognitive intervention, practice and evaluation in this study were done within the regular mathematics curriculum. Moreover, the activities used were based on the standards set by the Department of Education [11]. The whole metacognitive intervention took place for six weeks from October 3 to December 2, 2016 (with a two-week break in between), covering the entire unit of Grade 7 Algebra. After the intervention, post-test for the Jr. MAI was performed to examine how the intervention affected the Metacognitive Awareness of the students in Mathematics.

To ensure that the Metacognitive intervention would be performed according to plan, the teacher was observed for five times (once a week) and was monitored as to how well he was able to follow the process of the intervention. The observers, which consist of Grade 7 Mathematics teachers, were made sure to be knowledgeable of the Metacognitive strategies employed in the class. A sit-down meeting was conducted with them by the researchers for the discussion on the essentials of metacognition and metacognitive strategies that were used in the class. An observation checklist containing the essential steps of the model was used during the observations for monitoring.

Quantitative data on learners' metacognitive awareness were obtained from the Jr. Metacognitive Awareness Inventory (Jr. MAI), an 18-item self-report instrument developed by Sperling, Howard, Miller \& Murphy [12] that is used to assess the metacognition of children from 3rd to 9th Grade in two major components: Knowledge of Cognition and Regulation of Cognition. It was adopted with permission from the main author, Dr. Rayne Sperling.

Qualitative data were acquired by means of student interviews, Focus Group Discussions (FGD) with the observers, and analysis of learners' outputs during the metacognitive intervention process. The research design of 
this study tried to explore how the findings from the qualitative phase of the study support the findings from the quantitative phase regarding the effect of the metacognitive intervention using I.M.P.R.O.V.E. model on learner metacognition.

A learning plan was used by the teacher to help him structure and utilize the I.M.P.R.O.V.E. Model in the implementation of the metacognitive intervention. The plan was constructed in consideration of the model's essential elements. Moreover, the plan was designed to be implemented for 6 weeks, having 4 sessions per week with 60 minutes per session, in consideration of the school's class schedule. The activities used per session were carefully chosen by the teacher to help in the proper implementation of this study.

As the metacognitive intervention took place during the 2nd Quarter of the academic year, Grade 7 Algebra or Foundations of Algebra was decided to be the area of concentration for the implementation. Also, it was the researchers' purpose to concentrate on this area as it appeared to be the least performed unit in Grade 7 Mathematics based on the results of students' performance in the past three academic years.

\section{Data Analysis}

This study went through quantitative and qualitative phases of data analysis.

The quantitative data on learners' metacognitive awareness in Mathematics were assessed using the following statistical treatments: (1) Mean - to determine the representative score of the respondents for the items in the Jr. MAI; (2)Standard Deviation - to determine the homogeneity of the responses for the group; (3)Paired Samples ttest - to determine whether or not there is a significant difference between the Grade 7 students' pre-test and post test results in the Jr. MAI; and (4) Cohen's d - to determine the effect size or the magnitude of the difference between the Grade 7 students' pre-test and post test results in Jr. MAI.

The qualitative data were examined using Content analysis. This involved classifying data into themes, with the aim to make sense of the data collected and to highlight the important messages, features or findings. These themes were then represented by statements that embodied the actual words of the respondents. In several instances, responses documented in verbatim that best represented group of statements were used to generalize the views of the respondents for a particular topic of interest.

\section{Results and Discussion}

\section{The Metacognitive Intervention Process}

The format for every class period of this study followed an individual-pair-group class sequence through which students work independently, then in pairs, and then by group. The groups were established in accordance with the process of the I.M.P.R.O.V.E. Model. That is, each set of students was composed of four learners with different levels of achievement, namely, high-achieving learner, low-achieving learner, and two average learners. These were determined using the academic performance of the students in Mathematics in the previous grading period.

During the six-week intervention, the students did activities that were anchored on a specific Metacognitive questioning strategy contained in prompt cards that served as a guide for them to comprehend the tasks, plan and implement the solution, monitor and evaluate the process of tasks. Some of the questions used were as follows: What is the task about? (Comprehension Question); What are the similarities or differences between the task at hand and tasks I have solved in the past? (Connection Question); What strategy/tactic/ principle can be used to solve the task and why? (Strategic Question); Is the solution reasonable? Can I solve/do the problem/ task differently? (Reflection Question). The reason behind these questions addressed was to arouse the students' opinions about themselves and the process was mainly to encourage them to ask questions themselves.

Worksheets were also used by the teacher to monitor the responses of the students on each learning activity. These were collected at the end of each session. They were examined by the researchers to see how the students developed in terms of their metacognitive ability. Some worksheets were given back to the students with comments to help them monitor their own development.

The intervention also involved purposeful reflective writing. Individual students submitted responses to a series of weekly reflective journal that required them to look back on previous weeks and/ or to think forward to the next week's class. The strategy enabled them to reflect on their learning during the previous week and to describe how their experiences and performance in class, and outside of class contributed to their learning. 


\section{Overall Metacognition Before and After the Intervention}

The overall mean scores of students regarding the pre-test and post-test obtained in the Jr. Metacognitive Awareness Inventory are presented in Table 1.

Table 1. Jr MAI Results of Grade 7 Students Prior to and After the Metacognitive Intervention ( $N=40)$

\begin{tabular}{|c|c|c|}
\hline & Pre-Test Mean & Post Test Mean \\
\hline Knowledge & 3.51 & 4.06 \\
\hline Cognition & & \\
\hline Regulation of Cognition & 3.28 & 3.98 \\
\hline Overall Mean & 3.39 & 4.02 \\
\hline
\end{tabular}

Analysis of individual items in the Jr. MAI revealed that 18 out of 18 item means increased from the pre-test and post-test measures. As can be seen in Table 1, the mean score in the Jr. MAI test for Knowledge about Cognition after the intervention increased from 3.51 to 4.06 (0.55 mean difference), falling under the Above Average level of Metacognitive Awareness. Knowledge about Cognition (KoC) refers to what individuals know about their own cognition, including their cognitive limitations ${ }^{4}$. In terms of the Regulation of Cognition (RoC), the grand mean score also increased from 3.28 (Average level) to 3.98 (Above average level) marking a 0.7 mean difference and one-level increase of awareness. Regulation of Cognition refers to the ability of individuals to use their metacognitive knowledge strategically. The overall mean score in the Jr MAI pre-test is 3.39, indicating that the students' metacognitive awareness prior to the intervention is at the Average level. This increased by 0.63 in the post-test with an overall mean score of 4.02, falling under the Above Average level.

Moreover, it can be observed from the table that the mean scores in the Jr. MAI Pre-test for both components of Metacognition ( $\mathrm{KoC}$ and $\mathrm{RoC}$ ) prior to the Metacognitive intervention are under different levels of metacognitive awareness. Mean scores for Knowledge of Cognition are slightly higher than for Regulation of Cognition. The above average level of awareness in the Knowledge about Cognition as compared to the average level of awareness for the Regulation of Cognition before the intervention implies that even if the students are already conscious of the way they think, learn and process information, they do not often use this to control their cognitive processes. There is a gap between knowing about the concepts, skills, or processes and applying them in practice. Also, one probable reason for this is that the students in the Grade 7 level are still in the process of acquiring and applying many of the regulatory skills assessed by the Jr. MAI. As expected, after the intervention, students' mean scores for both components already laid on the same level of awareness. Although the Regulation of Cognition component score continues to be slightly lower than the Knowledge of Cognition component score, the gap between the two is smaller than it was at the beginning of the study. This is perhaps because of the persistent metacognitive training they got in their mathematics class, where they were engaged in different selfregulation enhancing activities.

\section{Knowledge About Cognition and Regulation of Cognition}

The analysis of mean scores for sub-components within each component (Knowledge about Cognition and Regulation of Cognition) provides a closer look at patterns within the general results. Analysis at this level enabled the researcher to see the changes in students' sub-component scores that occurred over time after the metacognitive intervention and through more self-questioning opportunities the students had as they participated in their Mathematics class.

All sub-process scores under both components increased after utilizing the metacognitive intervention. In terms of the Knowledge about Cognition, as shown in table 2, the sub-component that got the highest mean increase after the metacognitive intervention was Declarative Knowledge, with a mean score of 4.39, landing in the High level of awareness. It marked a 0.64 mean difference from the mean score obtained prior to the intervention.

Table 2. Jr. MAI Scores of Grade 7 Students in terms of the Sub-components of Knowledge about Cognition and Regulation of Cognition before and after the Metacognitive Intervention

\begin{tabular}{|c|c|c|}
\hline & $\begin{array}{l}\text { Pre-Test } \\
\text { Mean }\end{array}$ & $\begin{array}{ll}\text { Post } & \text { Test } \\
\text { Mean } & \end{array}$ \\
\hline \multicolumn{3}{|l|}{ Knowledge about Cognition } \\
\hline Declarative Knowledge & 3.75 & 4.39 \\
\hline Procedural Knowledge & 3.47 & 3.96 \\
\hline Conditional Knowledge & 3.32 & 3.82 \\
\hline Overall Mean & 3.51 & 4.06 \\
\hline \multicolumn{3}{|l|}{ Regulation of Cognition } \\
\hline Planning & 3.13 & 3.85 \\
\hline Monitoring & 3.36 & 4.10 \\
\hline Evaluating & 3.21 & 3.83 \\
\hline Overall Mean & 3.28 & 3.98 \\
\hline
\end{tabular}


Declarative knowledge refers to what a person knows about himself as a learner and what influences his performance $^{4}$. Next to declarative knowledge is the Conditional Knowledge, having a mean score of 3.82- a 0.50 increase from the mean score of the Jr. MAI Pre-test, and remaining at the Above average level of awareness. Conditional Knowledge is about knowing when, where and why to use a particular procedure or strategy. However, among the three sub-components, it stayed to be the least used component having the lowest mean score. Procedural Knowledge had an increase of 0.49 , very close from the mean score improvement of the Conditional knowledge, with a mean score of 3.96. It also remained in the above average level of awareness in terms of knowing about strategies and other procedures.

In terms of the Regulation of Cognition, the sub-component that got the highest mean increase after the metacognitive intervention was Monitoring, with a score of 4.10, landing in the Above average level of awareness. It marked a 0.74 mean increase from the mean score obtained prior to the intervention. Monitoring refers to the self-testing skills needed to manage learning ${ }^{4}$. Very close behind Monitoring is the Planning, having a mean score of 3.85- a 0.73 increase from the mean score in the Jr. MAI Pre-test, and falling under the Above average level of awareness. Planning is the choice of appropriate strategies, allocation of resources and goal setting ${ }^{4}$. Evaluating appeared to be the least improved sub-component in the Metacognitive Regulation component in terms of mean, having an increase of 0.61 , with a mean result of 3.83 . Evaluating refers to the ability of a learner to assess his performance after a particular task, whether it is effective or ineffective.

Paired samples $t$-test was then utilized to evaluate the significance of the impact of a Metacognitive Intervention using the I.M.P.R.O.V.E. model on the Metacognitive Awareness and Mathematics Achievement of the Grade 7 Students. Table 3 shows the results:

\begin{tabular}{|c|c|c|c|c|c|c|c|}
\hline & Mean & Std. Dev & 95\% CI for Mean Diff. & $\mathbf{t}$ & df & Sig(2 tailed $)$ & d \\
\hline $\begin{array}{l}\text { Jr. MAI } \\
\text { Pre-Test- Post Test }\end{array}$ & 0.63 & 0.66 & $0.42,0.84$ & $\begin{array}{l}5.983 \\
(\mathrm{p}<0.05)\end{array}$ & 39 & 0.000 & 0.946 \\
\hline
\end{tabular}

As shown in the previous table, results indicate that there was a significant difference in their Metacognitive Awareness from the Jr. MAI Pre-test $(M=3.39, S D=0.50)$ to $J r$. MAI Post-test $(M=4.02, S D=0.41)$, with $t(39)$ $=5.983, \mathrm{p}<.05$ (two-tailed). The mean increase in the Jr. MAI scores was 0.63 with a $95 \%$ confidence interval ranging from 0.42 to 0.84 .

Table 4. Paired Samples t-test for the Knowledge about Cognition and its Sub-processes

\begin{tabular}{|c|c|c|c|c|c|c|c|}
\hline & Mean & $\begin{array}{l}\text { Std. } \\
\text { Dev }\end{array}$ & $\begin{array}{l}95 \% \text { CI for } \\
\text { Mean Diff. }\end{array}$ & $\begin{array}{l}\mathbf{T} \\
(* p<0.05)\end{array}$ & df & $\begin{array}{l}\text { Sig } \\
\text { (2 tailed) }\end{array}$ & d \\
\hline Knowledge about Cognition & 0.54 & 0.56 & $0.37,0.72$ & $6.157 *$ & 39 & 0.000 & 0.97 \\
\hline $\begin{array}{l}\text { - Declarative } \\
\text { Knowledge }\end{array}$ & 0.64 & 0.65 & $0.43,0.85$ & $6.233 *$ & 39 & 0.000 & 0.99 \\
\hline $\begin{array}{l}\text { - Procedural } \\
\text { Knowledge }\end{array}$ & 0.49 & 0.79 & $0.24,0.74$ & $3.928 *$ & 39 & 0.000 & 0.62 \\
\hline $\begin{array}{l}\bullet \quad \text { Conditional } \\
\text { Knowledge }\end{array}$ & 0.5 & 0.98 & $0.19,0.81$ & $3.242 *$ & 39 & 0.000 & 0.51 \\
\hline
\end{tabular}

To further analyze the difference in the results of the Jr. MAI determining the effect size or the magnitude of the difference between the Grade 7 students' pre-test and post test results, Cohen's d value was computed. The value of $\mathrm{d}=0.946$ indicates a large effect size.

The obtained results mean that the metacognitive intervention using the I.M.P.R.O.V.E. Model made a large, significant impact in enhancing the students' over-all Metacognitive awareness, which makes the model an effective tool to improve one's knowledge and ability to regulate his/her own thinking process. This is consistent with the findings of the previous studies conducted on the efficacy of the I.M.P.R.O.V.E. Model [9].

To gain a better understanding of the results, additional analysis on the significant differences for each component of Metacognition before and after the intervention was conducted by the researcher to determine how the use of the I.M.P.R.O.V.E. Model affected the students' Metacognition in terms of its subcomponents, the Knowledge about Cognition and Regulation of Cognition. The results are shown in Table 4.

Numerical findings in the table indicate that there was a significant difference on the students' knowledge about their cognition from the pre-test and post-test measures with $t(39)=6.157, \mathrm{p}<.05$ (two-tailed). The Cohen's 
$\mathrm{d}$ value for the said component was 0.97 which indicated a large effect size. In terms of the three subcomponents of Knowledge about Cognition such as Declarative

Knowledge, Procedural Knowledge, and Conditional Knowledge, all of them have showed a significant difference with $\mathrm{t}(39)$ equal to 6.233, 3.928, and 3.242, $\mathrm{p}<.05$ (two-tailed), respectively. However, the Cohen's d value obtained for each sub-process allows us to see which showed greater effect from the metacognitive intervention. The results are discussed as follows:

Among the three subscales, Declarative Knowledge appears to have the greatest magnitude of difference having the Cohen's d value of 0.99, which indicates a large effect size. This means that the students greatly improved in terms of what they know about the way they think and process information as learner, which is an important factor before they are able to process or use their critical thinking during any activity. Considering that this domain already fell under the Above average level of awareness prior to the intervention, the improvement to High level of awareness could be attributed to the use of the metacognitive questions in the I.M.P.R.O.V.E. model as a means to stimulate or activate the declarative knowledge of students during the Mathematics instruction.

Procedural Knowledge, on the other hand, indicated a medium effect size with a d value of 0.62. This means that a moderate improvement took place on the students' knowledge on how to apply specific strategies to various situations. This aspect of metacognition is essential to be developed to students as this requires them to obtain knowledge through discovery, cooperative learning and problem solving. More often, strategies such as modelling and thinking-aloud provide an opportunity for them to activate their procedural knowledge, which were used in the first few sessions of the implementation of the I.M.P.R.O.V.E. Model.

Similarly, the third component, Conditional Knowledge, indicated a moderate effect of difference having a d value of 0.51 ; however, it got the least improvement compared to the other subscales. A body of literature reveals that this aspect of Metacognitive knowledge appears to be the most difficult subscale to be developed as it

Table 6. Paired Samples t-test for the Regulation of Cognition and its Sub-processes

\begin{tabular}{|c|c|c|c|c|c|c|c|}
\hline & Mean & $\begin{array}{l}\text { Std. } \\
\text { Dev }\end{array}$ & $\begin{array}{l}\text { 95\% CI for Mean } \\
\text { Diff. }\end{array}$ & $\begin{array}{l}\mathrm{T} \\
(* \mathrm{p}<0.05)\end{array}$ & df & $\begin{array}{l}\text { Sig(2 } \\
\text { tailed })\end{array}$ & d \\
\hline Regulation of Cognition & 0.71 & 0.81 & $0.45,0.97$ & $5.535 *$ & 39 & 0.000 & 0.88 \\
\hline Planning & 0.73 & 1.3 & $0.31,1.14$ & $3.539 *$ & 39 & 0.000 & 0.56 \\
\hline Monitoring & 0.74 & 0.74 & $0.50,0.98$ & $6.345^{*}$ & 39 & 0.000 & 1.00 \\
\hline Evaluating & 0.61 & 1.22 & $0.22,1.00$ & $3.184 *$ & 39 & 0.000 & 0.50 \\
\hline
\end{tabular}

requires the use of both Declarative and Procedural knowledge to situations with certain conditions considered. Possessing Declarative and Procedural knowledge to perform a task does not guarantee that a student will perform it well. Knowing what strategies and how to apply them to learning situations is important, but knowing when and why to apply them demands a deeper skill-training. Many students of Mathematics know many important concepts and strategies for solving problems, but still tend to fail because they do not know when to use them appropriately.

Table 5 shows the Paired samples t-test results for Regulation of Cognition and its subscales before and after the metacognitive intervention.

The table reveals that there was a significant difference on the students' regulation of cognition from the pretest and post-test measures with $\mathrm{t}(39)=5.535, \mathrm{p}<.05$ (two-tailed). The Cohen's $\mathrm{d}$ value for the said component was 0.88 which indicated a large effect size. All three subcomponents of Regulation of Cognition such as Planning, Monitoring and Evaluation have showed significant differences from the pre-test and post-test in the Jr. MAI with $\mathrm{t}(39)$ equal to $3.539,6.345$, and 3.184, $\mathrm{p}<.05$ (two-tailed), respectively. The Cohen's d value obtained for each sub-process provides us data which showed greater effect from the metacognitive intervention. The results are discussed as follows:

Monitoring is revealed to have the greatest improvement in terms of the effect size for the Regulation of Cognition with a $\mathrm{d}$ value of 1.00 , indicating a large significant difference. This is perhaps due to the variety of questions used by the teacher in every session of the intervention that ask the learners to monitor their progress in class such as:

"Is the strategy that you are using working, or you need to try something different?", "What are you still unsure about?"; "Does your solution work?"; "How do you think the solution is correct?"; and "How might you convince us that your way is the easiest way?" Moreover, the daily oral reflections done by the students during class discussions as well as their weekly journal writing permit them to monitor and assess themselves as to how well they have been performing in the class. In an interview with Avril (a pseudonym), she said that it became easier for her to remember and apply concepts in Algebra when she keeps an eye on her progress. She said, 
"I think, sir, when you really pay attention to what and how well you are learning in class, your learning improves. In my case, I tend to remember when to use certain strategies to problems when I remember how I thought during the time that the concept was taught in class. Experience-wise, one tip to learn really is to pay attention while you're learning."

The student, based on her response, seemed to have discovered what would help her learn in her Math class, but what she just practically meant by her statement was that learners just have to monitor what they have learned in the class so far, what they still need to learn, and how fully they are learning the concept.

Planning indicated a medium effect size with a d value of 0.56 . This means that a moderate improvement took place on the students' ability to choose appropriate strategies, allocate resources, set goals, and budget time. Planning is the initial phase of self-regulation. Perhaps, the ability to decide on which strategies should be used for every start of the activity in the class is difficult to be developed on students. This is probably the reason why there is a big difference on the effect sizes of Planning and Monitoring. It may be inferred that it was a way easier for the students to develop monitoring skills than to plan what to do for specific tasks. This aspect is what actually separates an expert learner from a novice learner in a class activity. For instance, an expert learner, when given a task, is able to plan on a wide-ranging level at the start of a task, whereas, the novice learner, will not be able to see the bigger picture. This has been observed by the research in a group conversation during the students' group activity. Royette (a pseudonym), who happened to be the high-achieving learner in the group, was the one who facilitated the group and initiated the idea what strategy could be used for solving a word problem. On the other hand, Carl, who happened to be a low-achieving learner, was just passive during the activity.

Evaluation also had a medium significant effect size having a d value of 0.50 . A moderate improvement also took place on the students' ability to evaluate their learning processes. As important as the other subcomponents, this component allows the students to go back and analyze their performance in class and determine what strategies became useful to their learning. Figure 1 shows Avril's evaluation of her performance in Mathematics after the fifth week of metacognitive intervention.

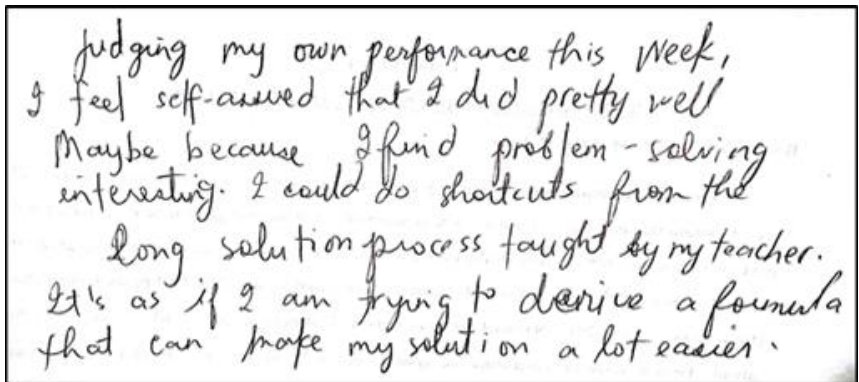

Figure 1. Avril's evaluation of her week 5 performance in Mathematics

The opportunity given to students to assess their performance at the end of each week allows them to know the areas that they think are their strengths. As presented in figure 5, it clearly shows that Avril showed interest in the answering problem solving questions. It manifested in her performance in the class based on the high scores she got from the formative assessments on problem solving. Similar to Planning, Evaluation is also difficult to develop to students. Perhaps, it would help students in the evaluation aspect of self-regulation if they are always asked to identify the strategies they utilize in class and why they choose these strategies, allot time for them to share ideas to their classmates, before evaluating their overall performance and assessing their strengths and weaknesses throughout the task.

Nevertheless, the above findings indicate that the students have significantly increased their regulatory skills, whether the impact was big or small. Moreover, the findings of this aspect of the study also mean that by consistently getting themselves involved into metacognitive-enhancing activities with the help of the I.M.P.R.O.V.E. Model, they could become expert learners who could recognize and acknowledge their own strengths and weaknesses, plan the necessary adjustments, monitor their understanding and comprehension throughout the tasks, and evaluate their own learning.

\section{Emergent Issues on the Utilization of the Metacognitive Intervention Using I.M.P.R.O.V.E Model}

\section{Questions that Direct Student Learning}

The use of Metacognitive Questioning in the I.M.P.R.O.V.E. Model through prompt cards during the metacognitive intervention became a good way to systematize the development of students' Metacognition in this study. During the first few sessions, it was observed that the students in their respective groups were not used to asking themselves and their group members questions about the way they process information in solving 
Mathematics problems. Although they already have prompt cards as a guide for their self-addressed questions, they tend to skip, rush and go directly to the solution of the problems, which was the usual thing that they do in their Mathematics classes. The teacher had to spend several minutes per group per session to guide them in utilizing the prompt cards correctly. It took about more than a week for the students to become fully trained on the process of metacognitive questioning using the cards.

A specific problem answered in the class will be used as an example to show how the students under study responded to the use of prompt cards:

Problem (Week 5, Session 2): Ben is eight years older than Sarah. Ten years ago, Ben is twice as old as Sarah. Currently, how old is each of them?

\section{Comprehension Question}

The comprehension question asks the students to reflect on a problem before solving it. To answer a comprehension question, students have to read the problem, describe the relevant concepts in their own words, and try to understand what the concepts meant. When the question, "What is the problem about?" was asked, this was how one group (Group A) responded to the question in one of their MI sessions:

Royette: “OK. Let's see... The problem asks about Ben and Sarah's current age. So this is an example of an Age problem."

Alex: "Yes, I agree. Umm, but there are different ways of answering Age problems. Which one are we going to use?"

Royette: "Let's try to check first the statements. It was said that Ben is the older person. He is older than Sarah by 8 years. Also, it was said that Ben is twice as old as Sarah ten years ago. I think we have to use a table to represent values."

Analyzing the conversation of the students above, it can be said that the students appropriately addressed the question since they did not rush into going directly to the solution of the problem. They examined first the use of all the statements in the problem. More often than not, students would tend to immediately start solving a word problem without attempting to comprehend the problem they need to solve.

In addition, it is in this type of question that the students are able to plan their solution for the problem. In the given situation, it was mentioned by one of the members that age problem can be answered using different ways.

One common mistake that students commit when answering a word problem is that they rely on the keywords of the problem rather than on its mathematical construct. For instance, in one of the activities done in the class, when they were asked to answer the problem, "If a ticket costs PhP 500 in Store A which is PhP 35 more than in Store B, how much does a ticket cost in Store B?", students mistakenly assume that "more" means addition. This makes them answer PhP 535 instead of $\mathrm{PhP} 465$.

To understand the problem is the first step in problem solving. If there is an effective way to address this question, that is through asking the students to restate the problem in their own words or to determine what type of problem it is.

\section{Connection Question}

The connection question asks the students of the similarities or differences between the problem at hand and the problems they have solved in the past. Here, they need to make connections by going deeper of the concept used in the given problem. The conversation shows how the same group of students responded to the question:

Angelo: "I think, the problem is similar to the problem Sir gave us (Shows a copy of the solution in the notebook). Let's first construct a table before we represent values."

Alex: "Yes. So, if we will represent Sarah as $x$, Ben will be represented as $x-8$. "

Royette: "No. Ben is older than Sarah so she should be represented as $x-8$."

Alex: "Ah, yes. But Ben can also be represented as $x+8$, then represent Sarah as $x$. ." 


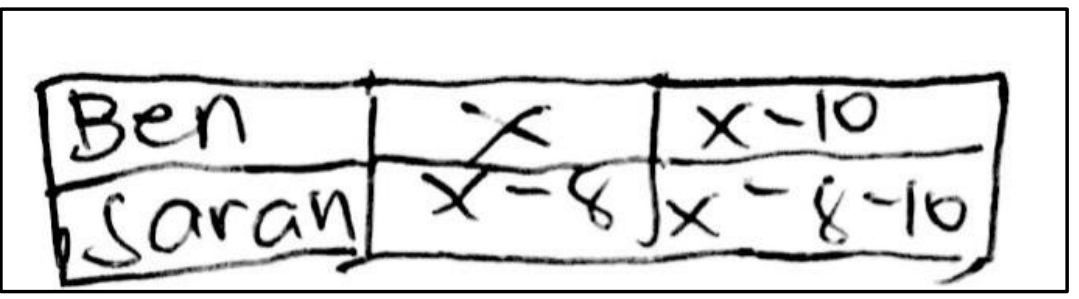

Figure 2. Group A's representation of Ben and Sarah's age

In the conversation, Alex committed a mistake representing Sarah as $x+8$. This was because in the illustrative example given by the teacher prior to the activity, the solution made use of addition in the representation to show that one of the persons in the problem is older than the other. Perhaps, the student used the pattern of the solution from the given example to answer the problem. There was a connection from the previous concept learned to the current problem being answered but used incorrectly. This gives an implication with regard to students' ability to go beyond what their teacher taught them. The ability of the students to connect prior knowledge to their present learning allows them to think of a variety of strategies appropriate to address the assigned tasks.

\section{Strategy Question}

Strategy question asks the students which strategies are appropriate for solving the given problem and for what reasons. The conversation below shows how the strategic question, "What strategy/ tactic/ principle can be used to solve the problem?", was addressed by the group:

Royette: "Umm, wait. Ah! If we are to make an equation, we have to use the representation of Ben and Sarah's age 10 years ago, $x$-10 and $x$-18. So, if we equate the two using the conditions given, the equation will be $x-10=2(x-18)$."

Alex: (Solves the equation) "If 2 will be distributed, the right side of the equation will become $2 x$-36. Then, by combining the like terms, we will have $36-10=2 x-x$. Then, merging both terms in the left and the right, we will get $26=x$. Thus, $x$ is equal to 26. Ben's age is 26."

Royette: “Therefore, if Ben's age is 26, since he is 8 years older, Sarah's age is 18 because 26-8=18."

$$
\begin{aligned}
x-10 & =x 002(x-18) \\
x-10 & =2 x-36 \\
36-10 & =2 x-x \\
26 & =x \quad \text { Sarah: } 18
\end{aligned}
$$

Figure 3.Group A's Algebraic Solution to the Problem

Based on the conversation, it can be said that the students did not directly answer the strategic question. However, Royette used the question as a guide to get an idea of what should be done to answer the problem. From there, he discussed the thorough process of his solution to the other members, which in a way made him address the question.

The same question was answered by another group who was noticed to have used a different strategy. Figure 4 shows the solution of the said group using a different strategy:

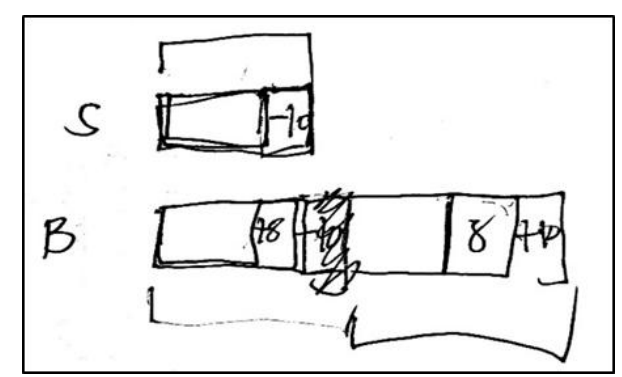

Figure 4. Group B'sBlock Modelling strategy 
The figure shows that the group of students attempted to use block modelling approach to answer the problem. However, with the limited time given to them, and due to the complexity of the figure formed based on the understanding of the members of the group, they were not able to finish the task. Perhaps, if they explored more on the use of the block modelling approach, they could have come up with the correct answer.

Having a web repertoire of strategies allows the students to decide the appropriateness of a specific strategy for a particular problem situation. It helps a lot for the students to plan, monitor, and evaluate their performance. Thus, strategy training for the learners is essential. However, strategies do not need to be explicitly taught all the time. Students would not remember everything that is just taught verbally. Literature states that students learn more by doing. If there is a good way to foster strategies to students, that is through Modelling by ThinkingAloud. If the teachers show how to use the strategies to the students in a way that they would know when and where to use the strategies, the students progressively get a range or selection of strategies.

\section{Reflection Question}

Reflection question asks the students to reflect on the solution process they did to solve the problem. It makes the students look back and check if their solution is reasonable, or if it could be solved in a different way. The conversation below shows how it was answered by the students:

Royette: We've obtained a correct answer, right?"

Alex: "Yes, I think our solution is reasonable enough. What if we answer it using a different representation?"

Angelo: "Which one, the $\mathrm{x}+8$ representation of Ben's age and $\mathrm{x}$ representation of Sarah's age?"

Alex: "Yes."

Royette: (Solves the equation using the new representation) "I got the same answer. Sarah's age is 18 since the value of $\mathrm{x}$ obtained is $18 . "$

Angelo: "Do you have any other solution?"

Carl: (Student 4 shows his solution) "Yes, I have. I used Trial and Error method."

\begin{tabular}{|c|c|}
\hline $\begin{array}{l}\text { START } \\
15+8=23-10 \\
16+8=24-10 \\
14+8=25-10= \\
18+8=26-10= \\
19+8=24-10= \\
20+8=28-10=\end{array}$ & $\begin{array}{l}5=13 \\
6=14 \\
7=15 \\
8=16 \\
9=19 \\
10: 18 \frac{18,26}{5}\end{array}$ \\
\hline
\end{tabular}

Figure 5. Carl's Trial and Error solution to the problem

The trial and error solution of Carl in the given problem (figure 5) clearly shows that even if the teacher never made use of the guess-and-check as a solution to any of the examples of Age problems, the learner used the strategy based on his own understanding to answer the problem. It can be observed that in the entire conversation of the group for that specific activity, Carl seemed to be passive and did not attempt to ask his group members regarding their solution. It was probably because he was making his own solution process in his mind that is based on his thinking ability (Regulation of Cognition). In his interview during the first week of the intervention, he mentioned that he found it difficult to decide when to use a strategy for a particular situation. Because of this, he was settling for his own strategies that he thought would work for a particular task. In Mathematics, particularly in problem solving, there are learners who really depend on their own understanding of the problem, especially if they find it hard to follow the solution process taught by the teacher, and there is nothing wrong with that. It even makes the Trial and error strategy primarily good for fields where the solution is the most important factor. What is essential is that the student knows when, where and how to use the strategy (Knowledge about Cognition). One of the most powerful advantages to this technique is that it does not require a learner to have a lot of knowledge. However, it may require him to have large amounts of patience and time to process things.

\section{Enriching Students' Metacognitive Experience}

To train the students think about their own thinking is effortful and time-consuming. But, the thing about creating a class environment that is grounded on Metacognition is that, students are exposed to a more meaningful approach. Teaching a subject matter nowadays does not only require students to know loads of information, but to know how to use the information they get. Through training Metacognition, students become active and effective 
learners. Thus, it is important to maximize the students' full potential through enriching their Metacognitive experience in class.

Aside from doing the standard metacognitive questioning embedded within the group activities with the use of prompt cards, individual and pair activities were also done to enrich the metacognitive ability of the students. The following metacognitive strategies were also employed:

- Modelling/ Thinking-Aloud

- $\quad \mathrm{KWL}$ (Know, Want to Know, Learned)

- Visualization (Use of Graphic Organizers)

- $\quad$ Pattern searching

- Working backwards

- Use of counter examples/ Error analysis

- Mnemonics

These strategies were used by the teacher one at a time within the intervention period to give the students enough space to adjust to the diversity of the activities. Some were taught explicitly on how they should be utilized in the class, while some were indirectly implemented.

\section{Use of Reflections in Mathematics}

The use of reflections has also been an important part of the Metacognitive intervention process as the students get the chance to assess their individual performance during the Math class sessions. Usually, the use of essays in the class are embedded in the students' Reflective Journals which they accomplish either every day or every end of the school week. In this study, aside from the standard weekly reflective journals, the use of essay questions was also done during the class discussions, orally. The advantage of doing so is that the teacher gets a more authentic response from the students when they are asked either on the spot or within a limited period of time. However, during the first few sessions, it was observed that the respondents were unfamiliar with the technique of answering essay questions in Math. This made it difficult for them to express themselves. Moreover, some are quite hesitant to express their opinions in front of the others. One student mentioned in his weekly reflective journal output,

“...I also felt a little bit unsatisfied because I have these questions in my mind that still needs answers by my teacher. The problem is I cannot explain or rather I do not know how to transmit those questions orally."

On the other hand, when the selected students were asked during the interview sessions, they said that they find the use of essay questions helpful for them to reflect on their answers and determine their possible errors in the activities. One student commented,

"Through the specific personal questions (reflective questions) that were asked in our class, I think we become more aware of the things we know and do not know, which makes it easier for us to learn our lessons."

As it appears on the students' performance in their Mathematics class after the intervention period, the use of essay questions became useful in monitoring both metacognitive components (Knowledge of Cognition and Regulation of Cognition) as the learners had the chance to reflect on their own strong and weak areas during a class activity. Its use in the Mathematics instruction became a technique that combined metacognitive processing with learning. It gave the students the opportunity to make a descriptive feedback about themselves so that they can gain greater confidence and experience greater success in class. Through making reflections, they can explore the ways of using learning strategies consciously and of adjusting the learning process to the real situations. Thus, students in the class must be really trained to know how to do reflections on their performance.

\section{Assessment of the Metacognitive Intervention by the Students and Teacher Observers}

The use of the I.M.P.R.O.V.E. Model in the class gained positive responses from the teacher observers and student participants as a good intervention tool to enhance students' Metacognitive Awareness.

Cooperative Learning was mentioned to be an essential part of their learning during the implementation. As many of the metacognitive enhancements happened during the group activities, the use of cooperative learning also became a contributory factor in the success of the activities. According to the students, the success of a group activity could also be attributed to the success of their cooperative learning. One student mentioned, 
" In using the prompt cards, there is a need to interact between the group members, so we are forced to cooperate with each other. In a way, we tend to know one another as to how we perform mathematically. Those who are not-so-good at Math are influenced by those who are doing well, while those who are good at Math are given the opportunity to share his/her ideas. So, it's a win-win situation for us."

When asked if they would recommend the use of the approach in their Mathematics lessons, the majority of them answered that they would definitely recommend the approach done by the teacher to be applied in their next lessons in Mathematics. According to them, the class became a lot more enthusiastic after applying the method. It made them more attentive to what was being taught, and thought they excelled in mathematics. The nature of the method was appealing. However, they pointed out some recommendations to improve the use of the model. Their suggestions were quoted as follows:

"While I approve to this strategy, some lessons were quite tedious, so I would recommend more time in discussions and more examples instead of having everything in a haste, so we can catch up better and not having the lessons all hurried to make way for the new topic. I would also suggest having "on-hands" activities more often, not only for mathematically gifted students can participate, but also those who would like to try to excel."

The teacher observers, on th other hand, unanimously lauded the use of the I.M.P.R.O.V.E. Model as a tool to teach the students with the aim of enhancing their metacognitive skills and performance in Mathematics. During one of the FGDs, one teacher mentioned that with the use of the model, the students tend to become active learners. It helped the students to learn to regulate their thinking as they worked on a task. Moreover, the use of the model was commended as it goes beyond the usual process of teaching the lessons. She said:

“... He (the teacher) gives out different activities for the students, not just the usual seatworks seen from books and modules. He would give out something where the student doesn't only solve, but also reflects. For example, in one of the seatworks, it asked what strategy was used for the problem, then the next question asked if there was another way to solve the problem. Through the method used, the teacher doesn't only see how the student solved the problem, but how the student analyzed it as well."

Another teacher stated that one remarkable strength of the method is that it was designed for heterogeneous classes. Since the students were grouped according to their mathematics performance, where students of all levels are represented in each group, opportunity was given for the advanced students to help those who are struggling in the subject. Thus, a much meaningful learning was achieved.

The results of the observation checklist used by the observers to determine whether the process of the model was correctly followed by the teacher indicated that $94 \%$ of the tasks on the MI process was observed.

A similar response from a student interview was stated by one of the observers which mentioned that the best feature of the model was the metacognitive questioning itself. The core of the model was to elicit the ability of the students to make reflections about themselves as they go through the activities of the lesson. The observer even praised the feasibility of implementing the approach in public schools. She added,

"Actually, the use of the I.M.P.R.O.V.E. Model in classrooms is not expensive to implement. Different to many other educational interventions, implementing the approach does not necessitate expensive, specialist equipment or changes to school infrastructure. The only price of implementing the method is the cost of professional development."

In addition, the I.M.P.R.O.V.E. strategy is said to be helpful in engaging the students in a more studentcentered learning, which is the major target of the $\mathrm{K}$ to 12 Curriculum nowadays. As the students are exposed to an interactive learning experience, they seem to strengthen their self-regulation skills, levels of interest and persistence in learning. However, while the approach of student-to-student interactions through metacognitive questioning typically focuses on allowing them to take control of their own learning, the teacher is still required to help in the development of their metacognitive skills. For example, the teacher needs to set clear learning objectives, demonstrate and monitor metacognitive strategies, and prompt and encourage his learners.

Objectives are also emphasized in one of the discussions of the teacher observers. According to them, daily session objectives are an important part of the learning process in class. This is why in any lesson plan, objectives come before any classroom activity. One observer suggested that to make sure that objectives for the day's lesson are achieved, the teacher may post "Today's targets" on the board. She mentioned that the class may be started by stating first the objectives for the session, then at the end of the discussion, see if every target is attained. Through this, everyone will be guided of the objectives for the class and nothing will be left behind. She added,

"The students need to understand what their learning objectives are so they can plan how to achieve them. The process of planning should involve learners identifying which strategies they already know that could be applied in a specific situation." 
Implementing a new teaching approach in classes generally takes time for the students to adapt to the nature of the strategy as it takes the class in a whole different perspective. Transforming the sessions into an introspective type of discussion will have to take so much effort for both the teacher and the students. It was suggested by the teacher observers that the intervention, to be fully adapted by the students, should be done in a longer period. According to them, a quarter of training their Metacognitive awareness through the I.M.P.R.O.V.E. Model might just be forgotten, eventually. A continuous implementation will yield better results. This was addressed by the teacher by stating that the training that have been done for the past weeks were made sure to be effective enough to be developed by the students. Moreover, as commended by the observers, the teacher had been very hands-on with the activities employed to the class. In fact, in the first few sessions, about 15 minutes was spent by roving about the classroom, reviewing the progress of each group, and asking probing questions to help the individual groups clarify their thinking.

An opposing view was raised during one of the meetings of the observers and the teacher implementer. According to one of the observers, one remarkable downside of the technique is that it consumes so much time in a learning period. A 60 -minute period is just not enough for a meaningful learning to take place if a big part of it will be consumed for the group activity using the prompt cards. More time for the practice of the Mathematical skill or Math exercises should be given an emphasis. The teacher observers agreed that the strategy should only be used on lessons that require the students to analyze and solve such as problem solving. If the nature of the task does not involve problem solving, for instance, evaluation of algebraic expressions or graphing linear equations, the strategy needs not be employed anymore. While the strategy needs to be experienced by the students for the mastery of the approach and development of their metacognitive processes, it does not need to be done all the time.

In general, the findings of the present study are believed to contribute important information towards the integration of metacognitive instruction in teaching and learning process particularly the use of the I.M.P.R.O.V.E. Model so as to promote Metacognition and Mathematics achievement.

\section{Conclusion}

Based on the findings of the research, the following conclusions were drawn:

1. The quality of Mathematics education in the Philippines could be improved if Mathematics teachers and learners have adequate knowledge of what effective learning in mathematics entails, that is, if teachers promote a classroom culture that is grounded on Metacognition, and if learners know to regulate their learning processes.

2. Metacognitive knowledge and Metacognitive regulation should be interdependent. It helps a lot for a learner to improve his/her performance if he/she knows when and where to use appropriate strategies.

3. The Grade 7 students' Metacognitive awareness (Knowledge about Cognition and Regulation of Cognition) significantly improved after implementing a Metacognitive intervention using the I.M.P.R.O.V.E. Model into their regular Mathematics class. Specifically, it made a large significant impact on the students' Declarative Knowledge, and Monitoring skills, while a moderate significant impact was made on their Procedural Knowledge, Conditional Knowledge, Planning skills, and Evaluating skills. Thus, the I.M.P.R.O.V.E. Model appears to be an effective tool to enhance students' Metacognitive Awareness.

4. Findings of the study indicate that supporting Metacognition with I.M.P.R.O.V.E. model's selfmetacognitive questioning is a good vehicle to systematize the metacognitive sessions. Reflective prompts help students regulate their Metacognitive processes particularly in the Monitoring and Evaluation subcomponent. In addition, the I.M.P.R.O.V.E. strategy engages the students in a more student- centered learning, which seemed to strengthen their self-regulation skills, levels of interest and persistence in learning.

5. Despite the promise presented about the potential of enhancing students' Metacognitive awareness and Mathematics achievement though the successful implementation of the Metacognitive intervention using the I.M.P.R.O.V.E. Model, the challenge remains that the process demands a lot of time for the preparation of the lesson, not to mention the amount of commitment that teachers have to put for the execution of the activities. Time indeed impacts on the effective teaching-and-learning of mathematics.

\section{Limitations and Future Studies}

There are a number of realizations in the completion of this study. By and large, the intervention was lauded by the majority of the observers and the students and the process was generally found to be effective for enhancing student metacognitive. However, pedagogical implications worth reflecting were noted and a number of recommendations for future studies and implementation were raised such as: 
1.Implementation of Metacognitive interventions requires a significant faculty development. Future implementers of the intervention must be fully knowledgeable of the concept of Metacognition. Future studies may be done focusing on faculty Metacognitive training.

2.The findings of the intervention were based on the data gathered from a limited sample for a limited period of time. Thus, it is suggested that the same study be conducted to a bigger sample size with longer intervention period. The greater sample size and the longer the implementation lasts, the more substantial the study will become.

3. There are factors that may affect students' Metacognition such as individual personality, motivation, learning style, etc. Future research may take these factors into consideration while investigating the impact of the I.M.P.R.O.V.E. Model to students' Metacognitive Awareness and Mathematics achievement.

4.As the intervention took place within the public-school setting where the use of technology is an issue, it is suggested for researchers in the field to conduct a study on examining the impact of the I.M.P.R.O.V.E. Model in an environment where the use of electronic devices is a factor.

\section{Acknowledgement}

The authors would like to express their profund gratitude to the following people who have helped them in the completion of this study: Dr. Rayne S. Sperling from the Pennsylvania State University, for allowing them to use the instrument that her team developed רבר - the Jr. Metacognitive Awareness Inventory (Jr. MAI); Dr. Minie Rose Lapinid, Dr. Maricar S. Prudente, and Dr. Auxencia Limjap, for their support, encouragement, constructive criticism and direction over the course of this research; and Mrs. Nora Villalobos, Ms. Heidi Mabaquiao, and Mr. Julius Abel Galpao, for the validation of the research instruments

\section{References}

Education for All 2015 National Review Report: Philippines. (2015). Retrieved from: http://unesdoc.unesco.org/images/0023/002303/230331e.pdf

Department of Education. (2010). Discussion paper on the enhanced K to 12 education program. Pasig City: CEAP

Elipane, L. (2012). Towards the embodiment of competency standards: Incorporating the elements of Lesson Study in the pre-service mathematics teacher education in the Philippines. The Asia Pacific Education Researcher, 21(2).

Schraw, G., Crippen, K. J., \& Hartley, K. (2006). Promoting self-regulation in science education: Metacognition as part of a broader perspective on learning. Research in Science Education, 36, pp.111-139.

Acoba, M., Caubalejo, S., Montero, N., Punongbayan M., Tud, A. (2011) The Relationship of the Metacognitive Awareness of Students to their Mathematics Performance. Unpublished Thesis: Philippine Normal University.

Desoete, A. (2007). Evaluating and improving the mathematics teaching-learning process through metacognition. Electronic Journal of Research in Educational Psychology, 5(3), 705-730.

Ozsoy, G. (2011). An investigation of the relationship between metacognition and mathematics achievement. Asia Pacific Education Review, 12, 227-235.

Lin, X. (2001). Designing Metacognitive Activities. Educational Technology Research and Development, 49(2), 23-40.

Mevarech, Z. R. \&Fridkin, S. (2006). The effects of IMPROVE on mathematical knowledge, mathematical reasoning and meta-cognition. Meta-cognition Learning, 1, 85-97.

Stringer, E. T. (2008). Action research in education (2nd ed.). New Jersey: Pearson.

Department of Education (2013) $\mathrm{K}$ to 12 Curriculum Guide- MATHEMATICS. Retrieved from: http://www.deped.gov.ph/sites/default/files/Math\%20Curriculum\%20Guide\%20Grades\%20110\%20December\%202013

Sperling, R. A., Howard, B. C., Miller, L. A., \& Murphy, C. (2002). Measures of children's knowledge and regulation of cognition. Contemporary Educational Psychology, 27,51-79. 